\title{
Effects of Stray AC Interference on Corrosion Behavior of X70 Pipeline Steel in a Simulated Marine Soil Solution
}

\author{
Yingchao Li, Cheng Xu, Ronghua Zhang, Qiang Liu, Xinhua Wang ", Yingchun Chen ${ }^{* *}$ \\ College of Mechanical Engineering and Applied Electronics Technology, Beijing University of \\ Technology, 100 Ping Le Yuan, Chaoyang District, Beijing 100124, China \\ *E-mail: wangxinhua@bjut.edu.cn \\ ${ }^{* *}$ E-mail: yingchun.c@bjut.edu.cn
}

doi: $10.20964 / 2017.03 .18$

Received: 7 December 2016 / Accepted: 12 January 2017 / Published: 12 February 2017

\begin{abstract}
The effects of stray alternating current (AC) on the corrosion behavior of X70 high strength pipeline steel in a marine soil simulated solution was investigated. For a comparison, the study was operated in $3.5 \% \mathrm{NaCl}$ solution and with an application of $150 \mathrm{MPa}$ tensile stress as well. The electrochemical measurements of open circuit potential $(\mathrm{OCP})$ and potentiodynamic polarization were used to exam the electrochemical process on the X70 steel surface under AC interference. A digital camera and scanning electron microscope (SEM) were used to analysis the corrosion morphology. The results show that a $30 \mathrm{~A} / \mathrm{m}^{2} \mathrm{AC}$ interference slightly shifted the corrosion potential $-0.03 \mathrm{~V}$, while a $300 \mathrm{~A} / \mathrm{m}^{2} \mathrm{AC}$ signal changed the value as much as $-0.2 \mathrm{~V}$. It was well explained with a mathematic model of AC interference. The corrosion rate increased with the AC current density in all test conditions. A corrosion mechanism was proposed to describe the occurrence of AC corrosion on the X70 steel sample surface. A net anodic current, implying an anodic dissolution, was resulted from a complete cycle of AC interference. The corrosion morphology changed from uniform corrosion to pitting corrosion under the AC interference. Thus, stray AC promoted the localized corrosion.
\end{abstract}

Keywords: Stray alternating current corrosion, X70 pipeline steel, corrosion mechanism, corrosion morphology, simulated marine soil solution

\section{FULL TEXT}

(C) 2017 The Authors. Published by ESG (www.electrochemsci.org). This article is an open access article distributed under the terms and conditions of the Creative Commons Attribution license (http://creativecommons.org/licenses/by/4.0/). 